\title{
Comparison of carabid beetles (Col., Carabidae) assemblages in integrated and organic potato management
}

\section{Porównanie zgrupowań biegaczowatych (Col., Carabidae) w integrowanej i ekologicznej uprawie ziemniaka}

\author{
Katarzyna Nijak ${ }^{1}$, Agnieszka Kosewska², Bożena Kordan ${ }^{2}$
}

\section{Summary}

The aim of this study was to compare the species composition and structure of assemblages of ground beetles inhabiting integrated and organic potato plantations. The study was conducted in Winna Góra near Środa Wielkopolska in 2008 and 2012. Two potato fields were selected: organic and integrated. Ten Barber traps were placed on each field. In total 4496 specimens representing 39 Carabidae species were captured. Harpalus rufipes was the dominate species (approximately 50\%). Plant protection products did not have the negative impact on beneficial ground beetles communities.

Key words: carabid beetles, potato crops, chemical protection

\section{Streszczenie}

Badania miały na celu porównanie składu gatunkowego i struktur zgrupowań biegaczowatych zasiedlających integrowane i ekologiczne uprawy ziemniaka. Obserwacje prowadzono w Winnej Górze koło Środy Wielkopolskiej w latach 2008 i 2012. Do badań wybrano dwie uprawy ziemniaka: ekologiczną i integrowaną, na każdej z nich założono po 10 pułapek Barbera. Ogółem odłowiono 4496 osobników należących do 39 gatunków Carabidae. Najliczniej na badanych polach ziemniaka występował Harpalus rufipes (około $50 \%)$. Nie zaobserwowano negatywnego wpływu stosowania środków ochrony roślin na zgrupowania pożytecznych biegaczowatych.

Słowa kluczowe: biegaczowate, uprawy ziemniaka, ochrona chemiczna

\footnotetext{
Instytut Ochrony Roślin - Państwowy Instytut Badawczy

Władysława Węgorka 20, 60-318 Poznań

${ }^{2}$ Uniwersytet Warmińsko-Mazurski w Olsztynie

Katedra Fitopatologii i Entomologii

Prawocheńskiego 17, 10-720 Olsztyn

a.kosewska@uwm.edu.pl
} 


\section{Wstęp / Introduction}

Uprawy ziemniaka, podobnie jak uprawy innych roślin, narażone są na ataki ze strony licznych szkodników (Gabryś i Kordan 2012; Vincent i wsp. 2012). Ma to bezpośrednie odzwierciedlenie w pogarszaniu jakości plonów oraz stratach ekonomicznych (Kowalska i Kühne 2010). Jednakże tam, gdzie występują szkodniki, obecni są również ich wrogowie naturalni. Ich skuteczność w zwalczaniu szkodników zależy od wielu czynników, m.in. od ich liczebności, warunków meteorologicznych, sposobu uprawy gleby, ale też od stosowania różnego rodzaju środków ochrony roślin (Kromp 1990; Clark 1999; Jaworska 2006; Birkhofer i wsp. 2008; Kosewska i wsp. 2009; Nietupski 2012). Pomimo niewatpliwej korzyści ze stosowania zabiegów chemicznych, jaką jest wzrost plonów, zawsze należy mieć na uwadze dobro organizmów pożytecznych i postępować tak, aby ograniczyć straty w ich populacjach. Pożytecznymi organizmami, z których większość należy do nie wyspecjalizowanych drapieżców wspomagających rolnika w zwalczaniu szkodników, są chrząszcze z rodziny biegaczowatych (Thiele 1977). Ich obecność w agrocenozach jest ważna również ze względu na zachowanie bioróżnorodności i równowagi ekologicznej.

Celem badań było porównanie zgrupowań Carabidae występujących w ekologicznych i integrowanych uprawach ziemniaka.

\section{Materiały i metody / Materials and methods}

Badania terenowe prowadzono w Rolniczym Zakładzie Doświadczalnym w Winnej Górze od 26 maja do 8 września 2008 roku oraz od 14 maja do 20 sierpnia 2012 roku. Doświadczenie prowadzono na polu z uprawą ekologiczna, dla której przyjęto zasadę niestosowania środków ochrony roślin oraz $\mathrm{w}$ uprawie ziemniaka, dla której przewidziano integrowany program ochrony roślin. Powierzchnia każdego z pól wynosiła 0,46 ha. W 2008 roku były to ziemniaki odmiany Edena, w 2012 - odmiany Vineta. Badania fauny naziemnych Carabidae oparto na ciagłych jej odłowach pułapkami Barbera. Na każdym z wybranych pól umieszczono po 10 pułapek, które opróżniano co 14 dni.

Zebrany materiał analizowano pod względem składu gatunkowego, liczebności oraz struktury dominacji. Przyjęto klasy dominacji według Górnego i Grüma (1981).
Przy opracowaniu wyników posłużono się wskaźnikami ogólnej różnorodności gatunkowej Shannona-Weavera H' (Log Base 2,718), równomierności Pielou (J') oraz bogactwa gatunkowego Simpsona (D). Istotność różnic między średnimi oceniono na podstawie jednoczynnikowej analizy wariancji ANNOVA, przy poziomie istotności $\mathrm{p}<0,05$, używając pakietu STATISTICA 10. Podobieństwo zgrupowań biegaczowatych badanych siedlisk zilustrowano za pomocą dendrogramu Bray-Curtisa.

\section{Wyniki i dyskusja / Results and discussion}

W wyniku przeprowadzonych badań odłowiono łącznie 4496 osobników należących do 39 gatunków chrząszczy z rodziny Carabidae. Na polu z integrowaną ochroną ziemniaka odłowiono 1917 osobników należących do 34 gatunków, natomiast na polu z uprawą ekologiczną było ich 2579 z 33 gatunków. Są to wyniki zbliżone do wykazywanych przez innych autorów badających Carabidae w uprawach ziemniaka w Polsce (Kosewska i wsp. 2008), wyższe niż na Litwie (Bukejs 2009) oraz znacznie niższe niż w uprawach ziemniaka w Austrii (Kromp 1990; Traugott 1998). Ważnym wskaźnikiem opisującym zgrupowania biegaczowatych jest różnorodność gatunkowa. W uprawie integrowanej zaobserwowano wyższą różnorodność gatunkową (H') Carabidae (tab. 1). Może się to wiązać $\mathrm{z}$ niższą niż w uprawie ekologicznej liczebnością zgrupowania, przy nieznacznie, ale jednak wyższej liczbie gatunków. Wyższe bogactwo gatunkowe Simpsona (D) zaobserwowano natomiast na polu nieobjętym ochrona, co wiąże się z wysoką liczebnością gatunków pospolitych. Stwierdzono statystycznie istotne różnice w średnich wartościach liczby osobników $(\mathrm{F}=11,14 ; \mathrm{p}<0,01)$, wskaźnika różnorodności gatunkowej Shannona $(\mathrm{F}=6,94$; $\mathrm{p}<0,01)$, równomierności Pielou $(\mathrm{F}=7,15 ; \mathrm{p}<0,01)$ oraz bogactwa gatunkowego Simpsona $(\mathrm{F}=6,55$; $\mathrm{p}<0,01)$. Tylko różnice $\mathrm{w}$ średnich liczbach gatunków odławianych na polach integrowanych i ekologicznych były nieistotne statystycznie (tab. 2). Clark (1999) badając biegaczowate występujące na polach ekologicznych i konwencjonalnych uzyskał podobne wyniki. Stwierdził on, że w uprawie ekologicznej liczebność i bogactwo gatunkowe były wyższe, ale różnorodność gatunkowa przyjmowała wyższe wartości w uprawie konwencjonalnej.

Tabela 1. Wskaźniki opisujące zgrupowania Carabidae badanych upraw ziemniaka Table 1. Indicators described Carabidae communities in the studied potato fields

\begin{tabular}{l|c|c|c|c}
\hline \multicolumn{1}{c|}{ Rodzaj uprawy - Type of cultivate } & Integrowana - Integrated & \multicolumn{2}{c}{ Ekologiczna - Organic } \\
\hline Rok - Year & 2008 & 2012 & 2008 & 2012 \\
\hline Liczba osobników - Number of individuals & 1101 & 816 & 1788 & 791 \\
\hline Liczba gatunków - Number of species & 28 & 30 & 26 & 29 \\
\hline $\begin{array}{l}\text { Różnorodność (Shannon H' Log Base 2,718) } \\
\text { Diversity (Shannon H' Log Base 2.718) }\end{array}$ & 1,981 & 2,385 & 1,639 & 1,948 \\
\hline Wská́nik równomierności Pielou J' - Eveness (Pielou J') & 0,594 & 0,701 & 0,502 & 0,579 \\
\hline $\begin{array}{l}\text { Bogactwo gatunkowe (Simpson D) } \\
\text { Species richnes (Simpson D) }\end{array}$ & 0,26 & 0,15 & 0,346 & 0,32 \\
\hline
\end{tabular}


Tabela 2. Średnie: liczebność, bogactwo gatunkowe i wskaźniki różnorodności zgrupowań Carabidae badanych upraw ziemniaka Table 2. Means: abundance, species richness and diversity indices of Carabidae communities in the studied potato fields

\begin{tabular}{|c|c|c|c|c|}
\hline \multirow{2}{*}{$\begin{array}{l}\text { Wskaźniki } \\
\text { Indices }\end{array}$} & \multicolumn{2}{|c|}{$\begin{array}{l}\text { Uprawa integrowana } \\
\text { Integrated cultivate }\end{array}$} & \multicolumn{2}{|c|}{$\begin{array}{c}\text { Uprawa ekologiczna } \\
\text { Organic cultivate }\end{array}$} \\
\hline & 2008 & 2012 & 2008 & 2012 \\
\hline \multirow{2}{*}{$\begin{array}{l}\text { Shannon H' Log Base } 2,718 \\
\text { Shannon H' Log Base } 2.718\end{array}$} & $1,85 \pm 0,07$ & $2,1 \pm 0,07$ & $1,59 \pm 0,06$ & $1,76 \pm 0,11$ \\
\hline & \multicolumn{4}{|c|}{$\mathrm{F}=6,94 ; \mathrm{p}<0,01$} \\
\hline \multirow{2}{*}{ Pielou J' } & $0,68 \pm 0,02$ & $0,77 \pm 0,03$ & $0,59 \pm 0,02$ & $0,66 \pm 0,04$ \\
\hline & \multicolumn{4}{|c|}{$\mathrm{F}=7,15 ; \mathrm{p}<0,01$} \\
\hline \multirow{2}{*}{ Simpson D } & $0,27 \pm 0,02$ & $0,18 \pm 0,02$ & $0,34 \pm 0,03$ & $0,32 \pm 0,04$ \\
\hline & \multicolumn{4}{|c|}{$\mathrm{F}=6,55 ; \mathrm{p}<0,01$} \\
\hline \multirow{2}{*}{$\begin{array}{l}\text { Średnia liczba osobników } \\
\text { Mean number of individuals }\end{array}$} & $110,1 \pm 11,18$ & $81,6 \pm 9,76$ & $178,8 \pm 21,27$ & $79,1 \pm 10,09$ \\
\hline & \multicolumn{4}{|c|}{$F=11,14 ; p<0,01$} \\
\hline \multirow{2}{*}{$\begin{array}{l}\text { Średnia liczba gatunków } \\
\text { Mean number of species }\end{array}$} & $15,3 \pm 0,26$ & $15,5 \pm 0,9$ & $15,2 \pm 0,55$ & $14,9 \pm 1,14$ \\
\hline & \multicolumn{4}{|c|}{-} \\
\hline
\end{tabular}

Tabela 3. Podział biegaczowatych badanych upraw ziemniaka według klas dominacji

Table 3. Specification of Carabid beetles in studied potato fields according to dominance classes

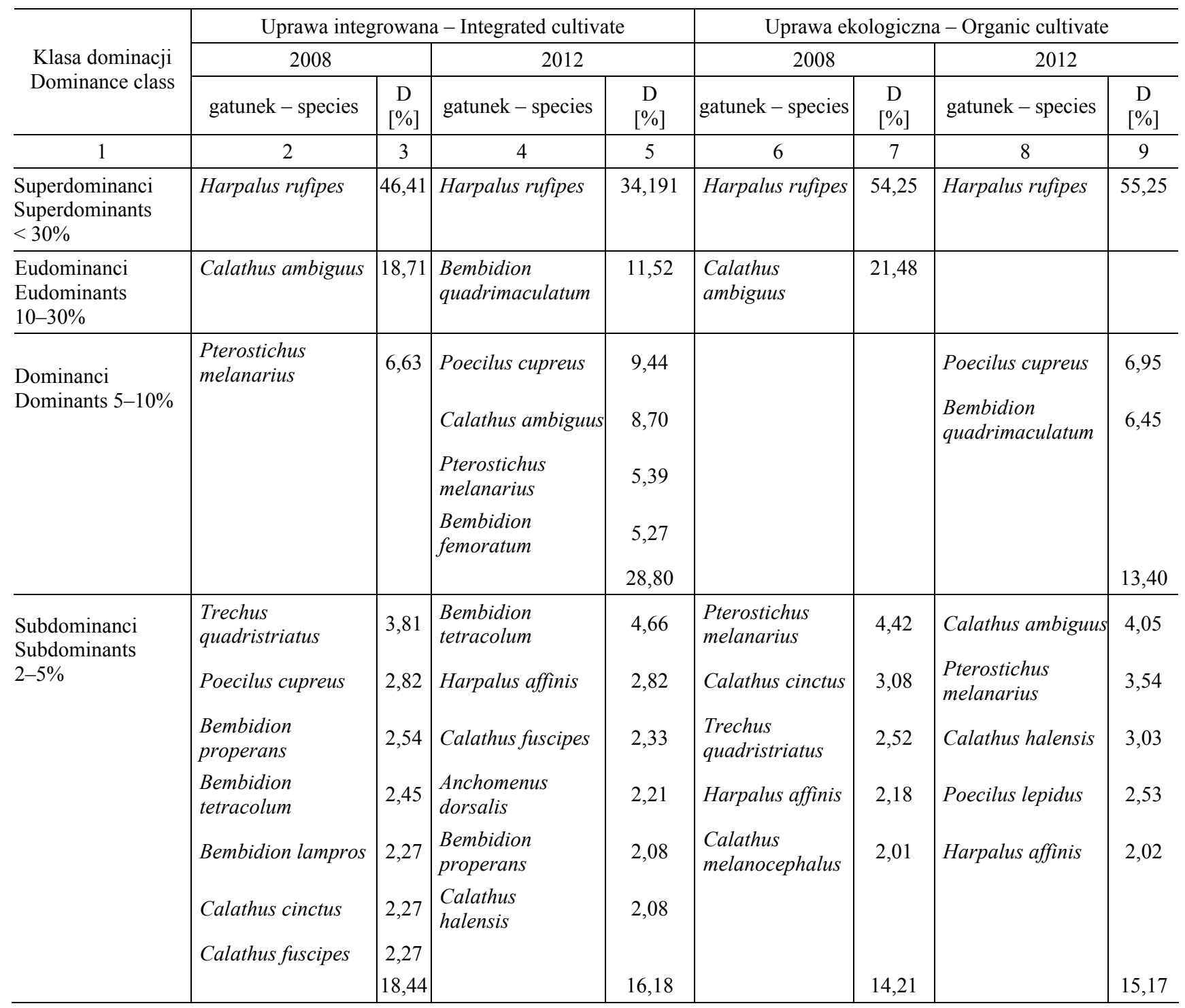




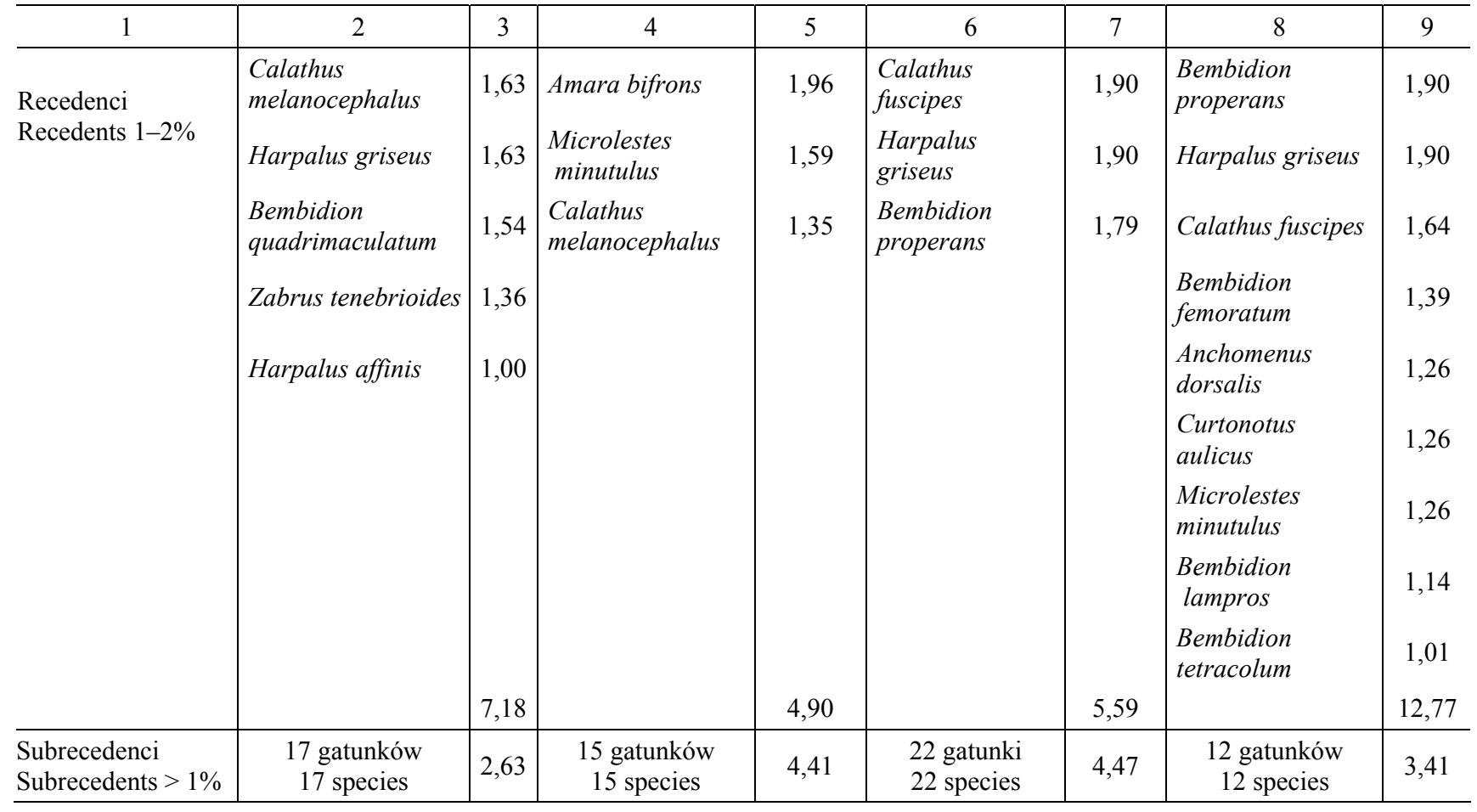

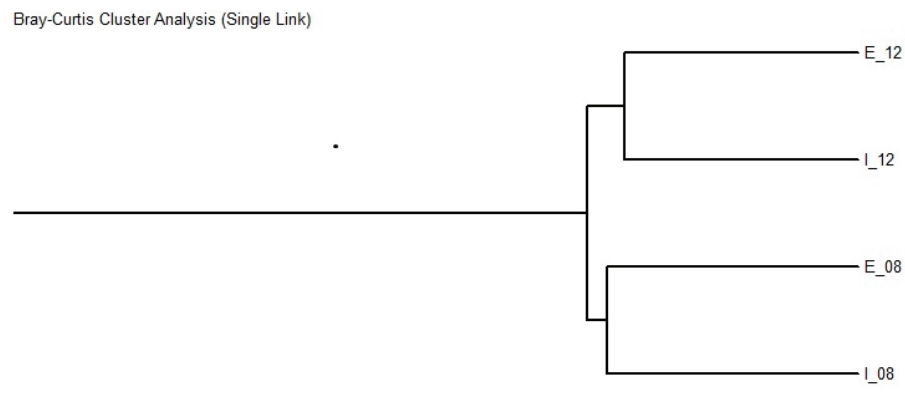

Rys. 1. Dendrogram podobieństw zgrupowań Carabidae badanych upraw ziemniaka

Fig. 1. Dendrogram of Carabidae assemblages similarity in the studied potato fields

Struktura dominacji ujawnia wyraźne zaburzenia zgrupowania Carabidae, co jednak jest typowe dla zgrupowań zamieszkujących pola uprawne, gdyż jak podaje Huruk (2006) presja czynników związanych z uprawą roślin może objawiać się zaburzeniami w strukturze dominacji. Zaznacza się wówczas wyraźna dysproporcja pomiędzy udziałami poszczególnych gatunków (Czechowski 1981). Na polu ekologicznym większość stanowił jeden gatunek - Harpalus rufipes uzyskując miano superdominanta (tab. 3). $\mathrm{Na}$ polu $\mathrm{z}$ ochroną integrowaną H. rufipes również był superdominantem, jednakże jego udział w zgrupowaniu nie przekraczał 50\%. Gatunek ten był również wykazywany jako licznie występujący w uprawach ziemniaków, w pracach innych autorów (Traugott 1998; Huruk 2006; Kosewska i wsp. 2008). Stosunki dominacyjne na obydwu typach pól były podobne. Zaobserwowano raczej zróżnicowanie w zależności od roku badań, a nie od zastosowanej na polu ochrony chemicznej. Do dokładniejszego ustalenia podobieństw i różnic między zgrupowaniami biegaczowatych badanych upraw ziemniaka zastosowano analizę skupień metodą dendrogramów (rys. 1). Dendrogram podobieństw zgrupowań Carabidae badanych pól wskazuje, że odrębne gałęzie tworzą biegaczowate obserwowane w poszczególnych latach. Współczynnik podobieństwa przekracza jednak $65 \%$, co świadczy o ich dużej homologii niezależnie od roku badań i zastosowanego sposobu uprawy. Analizując dodatkowo wpływ temperatury i opadów deszczu na aktywność biegaczowatych zauważono podobny trend (rys. 2). W roku 2012 niezależnie od średnich temperatur i opadów dynamika występowania Carabidae wyglądała podobnie na obydwu polach. Cztery lata wcześniej natomiast, kiedy w miesiącach letnich (lipiec i sierpień) odnotowano wysokie opady deszczu, zaobserwowano również w tym okresie wzrost aktywności biegaczowatych, szczególnie w sierpniu na polu z uprawą ekologiczną. 


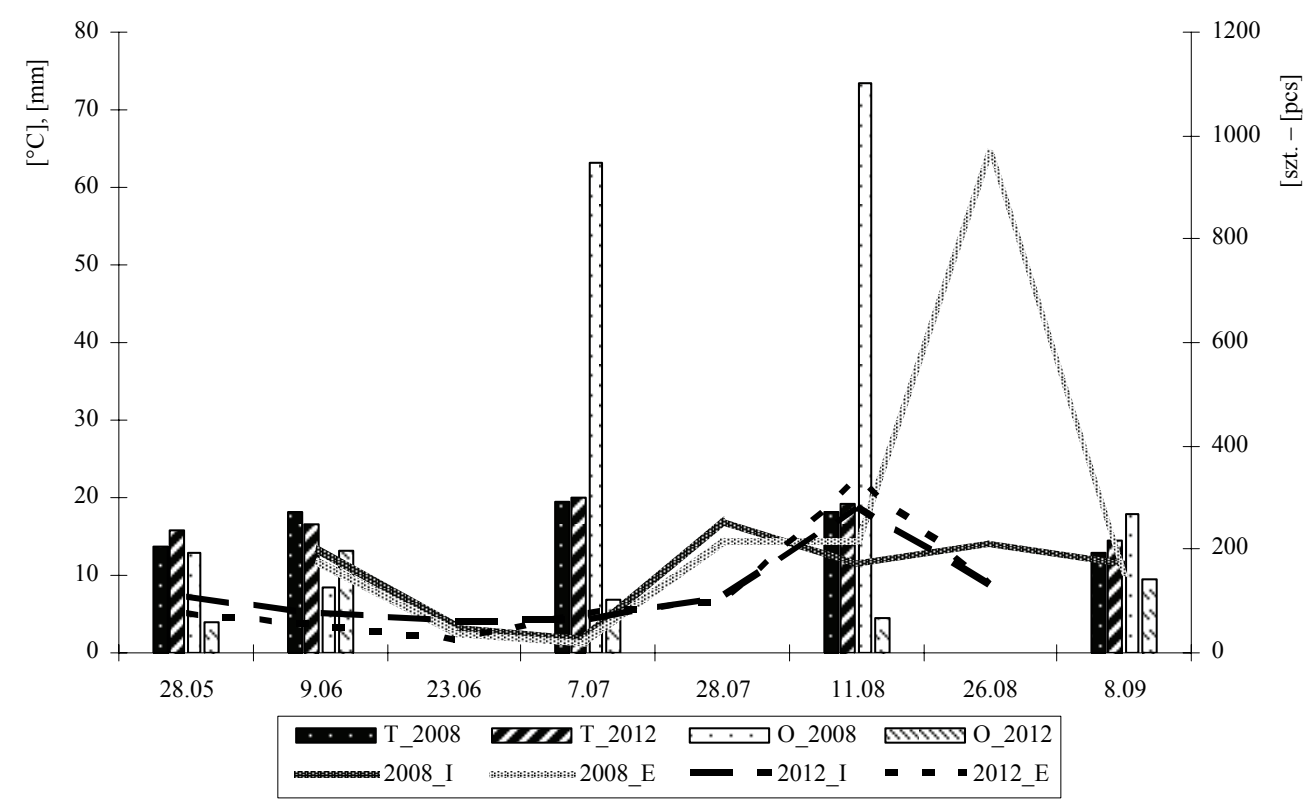

Objaśnienia - Explanations: T_2008, T_2012 - temperatura [ $\left.{ }^{\circ} \mathrm{C}\right]$ w latach 2008 i 2012 - temperature [ ${ }^{\circ} \mathrm{C}$ ] in 2008 and 2012 years; O_2008, O_2012 - opady deszczu [mm] w latach 2008 i 2012 - rain [mm] in 2008 and 2012 years; 2008_l, 2012_l - uprawa integrowana w latach 2008,2012 - integrated crop in 2008 and 2012 years; 2008_E, 2012_E - uprawa ekologiczna w latach 2008, 2012 - organic crop in 2008 and 2012 years

Rys. 2. Dynamika aktywności biegaczowatych na tle warunków pogodowych

Fig. 2. The dynamics of carabid beetles activity according to weather conditions

Można to thumaczyć przede wszystkim szczytem aktywności Carabidae spowodowanym pojawianiem się w tym czasie gatunków jesiennych, ale też można przypuszczać, że obfite opady deszczu powodowały spłukiwanie szkodników z roślin, które opadając na ziemię stanowiły łatwo dostępny pokarm dla badanych chrząszczy.

Zmiany entomofauny upraw rolniczych pod wpływem stosowania środków ochrony roślin analizowane były w pracach wielu autorów (Jaworska 1997; Clark 1999; Kromp 1999; Sokołowski 2000; Shah i wsp. 2003; Birkhofer i wsp. 2008; Werling i Gratton 2008; Kosewska i wsp. 2009). Sokołowski (2000) twierdzi, że zabiegi ochrony roślin mogą mieć wpływ na obniżenie liczebności Carabidae. Werling i Gratton (2008) uważają, że intensywnie uprawiane plantacje ziemniaków są miejscem niesprzyjającym występowaniu większości gatunków bie- gaczowatych. Twardowski i Pastuszko (2008) podają, że liczebność biegaczowatych na polach jest ściśle uzależniona od intensywności i rodzaju zabiegów agrotechnicznych. Jednakże nie ma to swojego odzwierciedlenia w badaniach przeprowadzonych na polach integrowanych i ekologicznych ziemniaka, gdzie zarówno liczba osobników, jak i gatunków biegaczowatych charakteryzowały się, wysokim podobieństwem.

\section{Wnioski / Conclusions}

1. Ochrona chemiczna w integrowanej uprawie ziemniaka nie wpływa negatywnie na zamieszkujące uprawę zgrupowania epigeicznych biegaczowatych.

\section{Literatura / References}

Birkhofer K., Fließbach A., Wise D.H., Scheu S. 2008. Generalist predators in organically and conventionally managed grass-clover fields: implications for conservation biological control. Ann. Appl. Biol. 153: 271-280.

Bukejs A. 2009. Complex of carabid beetles (Coleoptera: Carabidae) of potato fields agrocenosis in Eastern Latvia. Acta Zool. Lituan. 19 (3): $216-222$.

Clark M.S. 1999. Ground beetle abundance and community composition in conventional and organic tomato systems of California's Central Valley. Appl. Soil Ecol. 11: 199-206.

Czechowski W. 1981. Biegaczowate (Carabidae, Coleoptera). Fragm. Faun. 26 (12): 193-216.

Górny M., Grüm L. 1981. Metody Stosowane w Zoologii Gleby. PWN, Warszawa, 482 ss.

Gabryś B., Kordan B. 2012. Insect Pests Potato. Global perspectives on biology and management. Cultural control and other nonchemical methods. Academic Press-Elsevier, USA. Chapter 18: 517-541.

Huruk S. 2006. Porównanie struktur zgrupowań biegaczowatych (Coleoptera: Carabidae) łąk kośnych oraz przylegających do nich pól uprawnych. Wiad. Entomol. 25, Supl. 1: 9-32.

Jaworska T. 1997. Wpływ odchwaszczania na dynamikę populacji biegaczowatych (Carabidae, Coleoptera). Prog. Plant Prot./Post. Ochr. Roślin 37 (2): 235-237. 
Jaworska T. 2006. Wpływ zabiegów chemicznych w agrocenozach na chronione gatunki biegaczowatych (Coleoptera: Carabidae). Wiad. Entomol. 25, Supl. 2: 89-94.

Kosewska A., Nietupski M., Laszczak-Dawid A., Ciepielewska D. 2008. Zgrupowania epigeicznych biegaczowatych (Col. Carabidae) wybranych agrocenoz. Prog. Plant Prot./Post. Ochr. Roślin 48 (4): 1304-1308.

Kosewska A., Nietupski M., Ciepielewska D., Słomka W. 2009. Czynniki wpływające na struktury zgrupowań naziemnych biegaczowatych (Col., Carabidae) w wybranych uprawach zbóż. Prog. Plant Prot./Post. Ochr. Roślin 49 (3): 1035-1046.

Kowalska J., Kühne S. 2010. Effect of biological plant protection products on beneficial insects in organic potatoes crops. J. Res. Apll. Agr. Engin. 55 (3): 191-194.

Kromp B. 1990. Carabid beetles (Coleoptera, Carabidae) as bioindicators in biological and conventional farming in Austrian potato fields. Biol. Fertil. Soils 9: 182-187.

Kromp B. 1999. Carabid beetles in sustainable agriculture: a review on pest control efficacy, cultivation impacts and enhancement. Agric. Ecosys. Environ. 74: 187-228.

Nietupski M. 2012. Naziemne biegaczowate (Coleoptera: Carabidae) występujące w sadach jabłoniowych objętych różnymi systemami produkcji. Prog. Plant Prot./Post. Ochr. Roślin 52 (2): 360-365.

Shah P.A., Brooks D.R., Ashby J.E., Perry J.N., Woiwod I.P. 2003. Diversity and abundance of coleopteran fauna from organic and conventional management systems in southern England. Agr. Forest Entomol. 5: 51-60.

Sokołowski A. 2000. Ochrona upraw rolniczych, a drapieżne stawonogi naziemne. Prog. Plant Prot./Post. Ochr. Roślin 40 (2): $587-589$.

Thiele H.U. 1977. Carabid Beetles in Their Environments. Springer-Verlag, Berlin, 329 pp.

Traugott M. 1998. Larval and adult species composition, phenology and life cycles of carabid beetles (Coleoptera: Carabidae) in an organic potato field. Eur. J. Soil Biol. 34 (4): 198-197.

Twardowski J.P., Pastuszko K. 2008. Field margins in winter wheat agrocenosis as reservoirs of beneficial ground beetles (Col., Carabidae). J. Res. Appl. Agric. Engin. 53 (4): 123-127.

Vincent C., Alyokhin A., Giordanengo F. 2012. Insect Pests Potato. Global perspectives on biology and management. Potatoes and their pests. Academic Press-Elsevier, USA. Chapter 1: 3-8.

Werling B.P., Gratton C. 2008. Influence of field margins and landscape context on ground beetle diversity in Wisconsin (USA) potato fields. Agric. Ecosys. Environ. 128: 104-108. 